\title{
REVIEW
}

Open Access

\section{Does treatment method matter? A meta- analysis of the past 20 years of research on therapeutic interventions for self-harm and suicidal ideation in adolescents}

Oswald D. Kothgassner ${ }^{1}$, Kealagh Robinson ${ }^{2}$, Andreas Goreis ${ }^{3,4}$, Dennis Ougrin ${ }^{5}$ and Paul L. Plener ${ }^{1,6^{*}}$

\begin{abstract}
Background: Self-harm is a clinically relevant and prevalent behaviour which peaks in adolescence. Given the high prevalence of self-harm, the high levels of psychiatric comorbidity, and its role as a risk factor for suicide, delivering evidence-based care is critical.

Methods: We conducted a systematic review and meta-analysis of the literature on treating self-harm in adolescents (12-19years) published in the last 20 years, identifying 25 randomised controlled trials. We calculated the effect of treatment interventions relative to active control conditions in reducing self-harm, suicidal ideation and depressive symptoms.

Results: Overall, treatment interventions fared slightly better than active controls in decreasing self-harm $(d=0.13$, $95 \% \mathrm{Cl} 0.04-0.22, p=.004)$, suicidal ideation $(d=0.31,95 \% \mathrm{Cl} 0.12-0.50, p=.001)$ and depressive symptoms $(d=$ $0.22,95 \% \mathrm{Cl} 0.07-0.38, p=.006$ ). Subgroup analysis of specific therapies revealed moderate effects of DBT-A in reducing self-harm $(d=0.51,95 \% \mathrm{Cl} 0.18-0.85, p=.002)$ and suicidal ideation $(d=0.48,95 \% \mathrm{Cl} 0.17-0.80, p=.003)$, as well as moderate effects of family-centred therapy in the treating suicidal ideation $(d=0.58,95 \% \mathrm{Cl} 0.01-1.15$, $p=.049$ ).

\footnotetext{
*Correspondence: paul.plener@meduniwien.ac.at

'Department of Child and Adolescent Psychiatry, Medical University of Vienna, Vienna, Austria

${ }^{6}$ Department of Child- and Adolescent Psychiatry and Psychotherapy, Medical University of Ulm, Ulm, Germany

Full list of author information is available at the end of the article
}

C C The Author(s). 2020 Open Access This article is licensed under a Creative Commons Attribution 4.0 International License, which permits use, sharing, adaptation, distribution and reproduction in any medium or format, as long as you give appropriate credit to the original author(s) and the source, provide a link to the Creative Commons licence, and indicate if changes were made. The images or other third party material in this article are included in the article's Creative Commons licence, unless indicated otherwise in a credit line to the material. If material is not included in the article's Creative Commons licence and your intended use is not permitted by statutory regulation or exceeds the permitted use, you will need to obtain permission directly from the copyright holder. To view a copy of this licence, visit http://creativecommons.org/licenses/by/4.0/. The Creative Commons Public Domain Dedication waiver (http://creativecommons.org/publicdomain/zero/1.0/) applies to the data made available in this article, unless otherwise stated in a credit line to the data. 
(Continued from previous page)

Conclusions: The findings of our meta-analysis indicate that, overall, currently available treatments are effective in treating self-harm, suicidal ideation, and depressive symptoms in adolescence. Although the treatment intervention conditions showed only small to moderate effects in comparison to active controls, these differences were statistically significant and are clinically important. Further research is needed to understand the reduction in selfharm within active controls, which may arise due to the natural course of self-harm, or the potential efficacy of treatment as usual and enhanced usual care. Given the significant reduction of self-harm in active control conditions, delivering effective care to a large number of adolescents with self-harm may require developing stepped-care models in clinical practice. Expensive and poorly available treatments should be targeted at young people who most need them.

Keywords: Self-harm, Suicidal ideation, Adolescence, Suicidal behaviour, Depression, Self-injury, Nonsuicidal selfinjury, NSSI

Self-harm, defined as intentional self-poisoning or injury of oneself irrespective of suicidal motivation or intent [26], is a behaviour widespread among adolescents. A recent review of 172 adolescent community samples reported a mean lifetime prevalence rate of $16.9 \%$ (range: 4.1 to $39.3 \%$ ), as well as a concerning trend to suggest that prevalence rates have increased in recent years [19]. Engagement in self-harm typically begins between 12 and 13 years old, peaks around 15 and 16 years old, and decreases in older adolescence and adulthood $[19,53,60]$. Thus, adolescence represents a key developmental period for self-harm prevention and intervention efforts [74].

Recent years have seen a debate about the nomenclature of self-harm. Whereas 'self-harm' includes both acts with or without suicidal intent, the term 'Nonsuicidal Self-Injury' (NSSI) describes the deliberate and direct destruction or alteration of body tissue in a manner that is socially unaccepted and that occurs without suicidal intent $[1,44]$, and therefore excludes suicidal attempts. Although the intention behind an act of self-injury is clinically relevant and of the utmost importance for clinical risk assessment [61,72], empirical evidence to support a clear distinction between self-injury with and without suicidal intent is lacking. A systematic review comparing studies that used a self-harm definition to those using an NSSI definition failed to find significant differences in mean lifetime prevalence rates $(16.1 \%$ versus $18.0 \%$ [54]), suggesting that in adolescent community samples this nomenclatory distinction is not evident.

Self-harm without suicidal intent also seems to play a role in the development of suicidal thoughts and behaviours. A growing body of evidence demonstrates that engaging in NSSI increases the risk of subsequent suicidal ideation, suicide attempts, and death by suicide $[5,7,27$, 63]. In particular, the interpersonal-psychological theory of suicidal behaviour argues that engaging in NSSI increases a person's capability for suicide by creating habituation to the psychophysiological aversiveness of self-injury [35], with recent evidence that engaging in NSSI is one of the strongest predictors of transition from suicidal thoughts to suicide attempts among adolescents [45]. In the context of this ongoing investigation, 'self-harm' is a pragmatic umbrella term that encompasses both suicidal behaviours (suicidal ideation and attempts) as well as NSSI [8]. Given the clinical significance of any form of self-harm, effective treatment interventions for reducing self-harm behaviours and suicidal ideation are urgently needed, as is seen as a toppriority for interventions such as Dialectical Behaviour Therapy [46].

To date, several systematic reviews and meta-analyses have evaluated the evidence for effective psychosocial treatment interventions for adolescents who self-harm. Among these, outcome criteria were mixed, with reviews focusing either on suicidal behaviours, NSSI, or selfharm. A Cochrane review evaluating 11 trials for adolescents with self-harm highlighted the paucity of evidence for treatment interventions, with (apart from two comparisons) all the evidence for specific interventions built from a single trial [28]. Little evidence was found to support the efficacy of group therapy, while MentalizationBased Therapy, Therapeutic Assessment, and Dialectical Behaviour Therapy for Adolescents (DBT-A) all warranted further evaluation [28].

Similarly, a systematic review of 29 treatment studies (including 18 RCTs) for suicidal and nonsuicidal selfinjurious thoughts and behaviours (SITBs) in youth found that no intervention met the standard to be classified as a 'well-established intervention', and only six interventions could be classified as 'probably efficacious' [21]. A meta-analysis focusing on suicide attempts or self-harm in adolescents evaluated evidence from 19 RCTs, finding that, following intervention, intervention groups had a lower proportion of adolescents with selfharm compared to active controls [57]. However, when focusing specifically on nonsuicidal self-harm (excluding 
suicide attempts), there was no statistically significant difference between treatment as usual (TAU) and intervention groups, although intervention conditions showed a trend towards better effectiveness compared to TAU [57]. Taken together, these reviews highlight the need for greater empirical investigation into the treatment of self-harm, including replication of promising treatment interventions.

More recently, an update to the systematic review of treatment interventions for SITBs in youth [21] focused exclusively on RCTs, including the 9 new trials available since 2015 [20]. In light of this additional evidence, DBT-A now met the standard to be classified as a 'wellestablished intervention' for reducing both self-harm and suicidal ideation and was classified as 'probably efficacious' for reducing NSSI and suicide attempts. Across several different treatment interventions, certain elements seemed to increase treatment efficacy, such as a family-centred approach, the inclusion of skills-training, and (except for suicide attempts) longer treatment duration. However, very few independent replications of treatment interventions were identified [20]. This limitation of the current evidence-base was also highlighted in another recent systematic review on interventions for adolescents with suicide attempts or self-harm, which found that, across 21 studies, only DBT-A and Cognitive Behavioural Therapy (CBT) demonstrated independent replications of treatment efficacy [33]. Thus, all systematic reviews and meta-analyses on the treatment of adolescent self-harm conclude that; i) evidence for the efficacy of therapeutic interventions is weak, and ii) independent replication of treatment effects are critically needed.

However, neither of the recent systematic reviews conducted a meta-analysis, and so point estimates of therapeutic effects, as well as factors that moderate these estimates, are currently unknown. As the literature on therapeutic interventions for adolescent self-harm has increased since 2015, we decided to conduct a metaanalysis of all controlled studies and RCTs published in the last 20 years, including the 12 studies not included in the most recent meta-analysis [57]. We also conduct sub-group analyses to assess for the effect of specific therapy types in reducing self-harm behaviours, suicidal ideation, and depressive symptoms, in order to gain a more nuanced understanding of the differential effects of treatment efficacy. Given that many trials showed efficacy in reducing self-harm both in the intervention and in the active control groups, we also investigated the effects of active controls in reducing self-harm. Control treatments such as Treatment As Usual (TAU) or Enhanced Usual Care (EUC) typically include frequent but rather unstructured sessions that are exemplary of routine clinical care. This warrants a focus on these control treatments, in addition to the investigation into the efficacy of treatment interventions over and above routine clinical care.

\section{Method \\ Search strategy and inclusion criteria}

A search of Google Scholar and PubMed databases was conducted using the keywords "Self-harm", "Self-injury", "Suicidal behaviour", "Suicidal ideation", "Cutting", "Suicide" AND "Adolescents", "Therapy" OR "Intervention" from December 1999 until December 2019.

Studies were included in the meta-analysis if they reported a randomized controlled trial (RCT) comparing therapeutic interventions with treatment-as-usual, and reported outcomes for self-harm and/or suicidal ideation in adolescents aged 12 to 19 . We included trials in which the majority of participants engaged in self-harm at least once, but studies in which only a minority $(<50 \%)$ of the sample had engaged in self-harm or suicidal behaviour, or study populations where the majority of participants had neurological or developmental disorders (e.g., autism) were excluded. We also excluded studies focusing solely on pharmacological treatments as well as uncontrolled studies (e.g., pre-post evaluations). No limitations on language or publication status were invoked.

We analysed the frequency of self-harm episodes and suicidal ideation as the primary outcome measures, with symptoms of depression as a secondary outcome measure, if reported. To analyse the effect of control interventions from pre- to post-measurement, we computed the standardized mean difference (Cohen's $d$ ) based on the means and standard deviations [16] of self-harm, depressive symptoms, and suicidal ideation before and after the control interventions. The title, abstract, and main text of each study were examined, with the exclusion of documents occurring at each stage (see Fig. 1). The initial search generated 1536 results. The title and abstracts were screened for eligibility and full-text papers were obtained where necessary to evaluate inclusion. After screening, 25 studies--all peer-reviewed journal articles--were identified and included in our meta-analysis.

\section{Data extraction and analysis}

Data from included studies were entered into a spreadsheet independently by two authors (ODK and KR) and differences were reviewed until consensus was reached. For each study included in the meta-analysis, we coded sample and intervention characteristics. The primary outcome was the standardized mean difference (Cohen's d) in self-harm measured post-intervention. Secondary outcomes included Cohen's $d$ for depressive symptoms and suicidal ideation as assessed via various self-report measures in therapeutic intervention and active control conditions measured post-intervention. Mean, standard deviations and sample sizes were retrieved and inserted 
Records identified through database searching $(n=1536)$

(Google Scholar $n=1143$, PubMed $n=393$ ) $(n=25)$

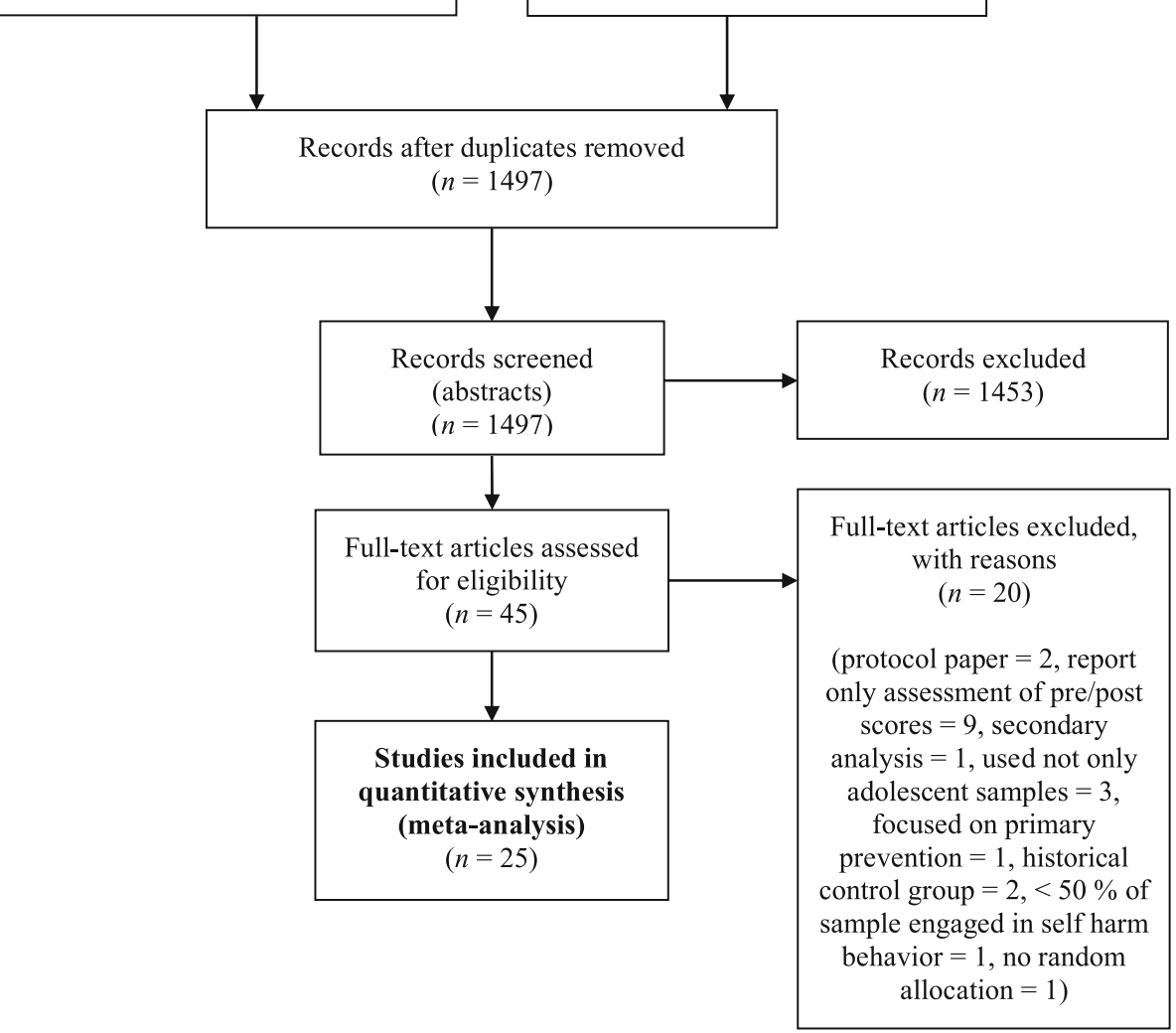

Additional records identified through other sources $(n=4)$

Fig. 1 PRISMA flowchart showing the screening, exclusion, and inclusion criteria

in a spreadsheet. If means or standard deviations were not reported in studies or supplemental materials, conversion via Revman [9] or formulas [4] were conducted. If episodes of self-harm were reported as proportions or odds ratios, they were transformed to Cohen's $d$ via formulas provided in Lipsey and Wilson [42].

We computed the standardized mean difference (Cohen's $d$ ) between intervention and active controls as an indicator of the therapeutic intervention's efficacy using the formula $d=\left(M_{\text {Intervention }}-M_{\text {Control }}\right) / S D_{\text {pooled }}$, with the respective means of measurements for the intervention and active controls. Effect size calculations and subsequent meta-analysis were then conducted with the metafor package for R [71], which automatically corrects Cohen's $d$ for the potential positive bias in small samples [30]. Following established conventions [10], an effect size of 0.20 was considered a small effect, 0.50 a medium effect, and 0.80 a large effect. Random effects models were applied to estimate aggregated effect sizes. Heterogeneity across study outcomes was reported with
$I^{2}$ values, where $25 \%$ indicates low, 50\% moderate, and $75 \%$ high heterogeneity [32]. Egger's regressions were conducted to estimate publication bias [67], with adjusted effect sizes calculated using trim-and-fill analyses and, based on funnel plot asymmetry, numbers of imputed missing studies [17]. Moderator analysis (meta-regression) was conducted to test whether treatment duration moderated the effect of the therapeutic interventions. All data and analysis code are available on the Open Science Framework (DOI:https://doi.org/10. 17605/OSF.IO/VR52S).

\section{Results}

\section{Study characteristics}

In total, 25 studies were identified (see Table 1), all of which were RCTs. The 25 studies comprised 2962 participants in total, of which 1515 received therapeutic interventions and 1447 received active control treatments.

The most common therapeutic interventions investigated were either family-centred therapy $(n=5,20 \%)$ or 


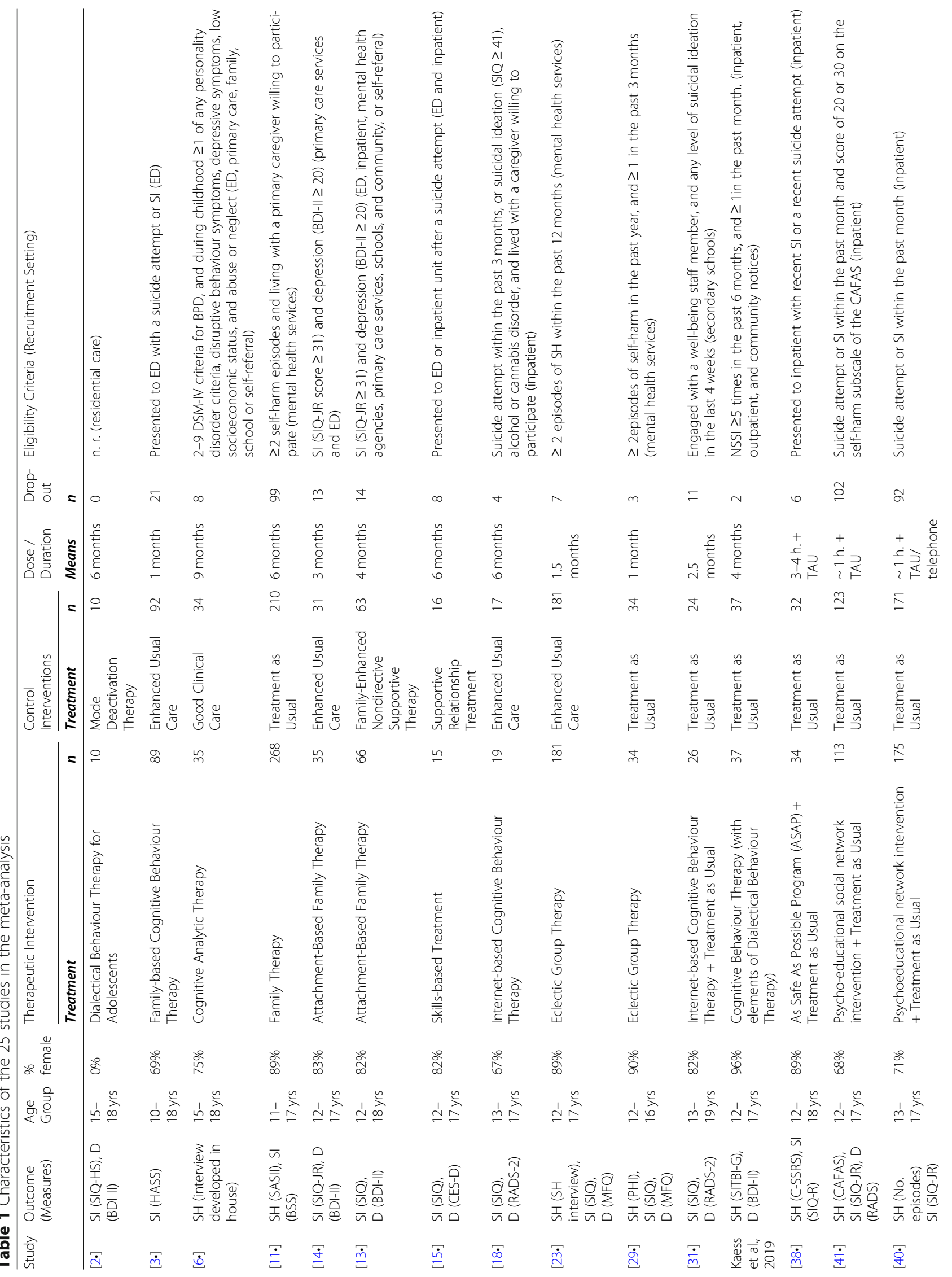




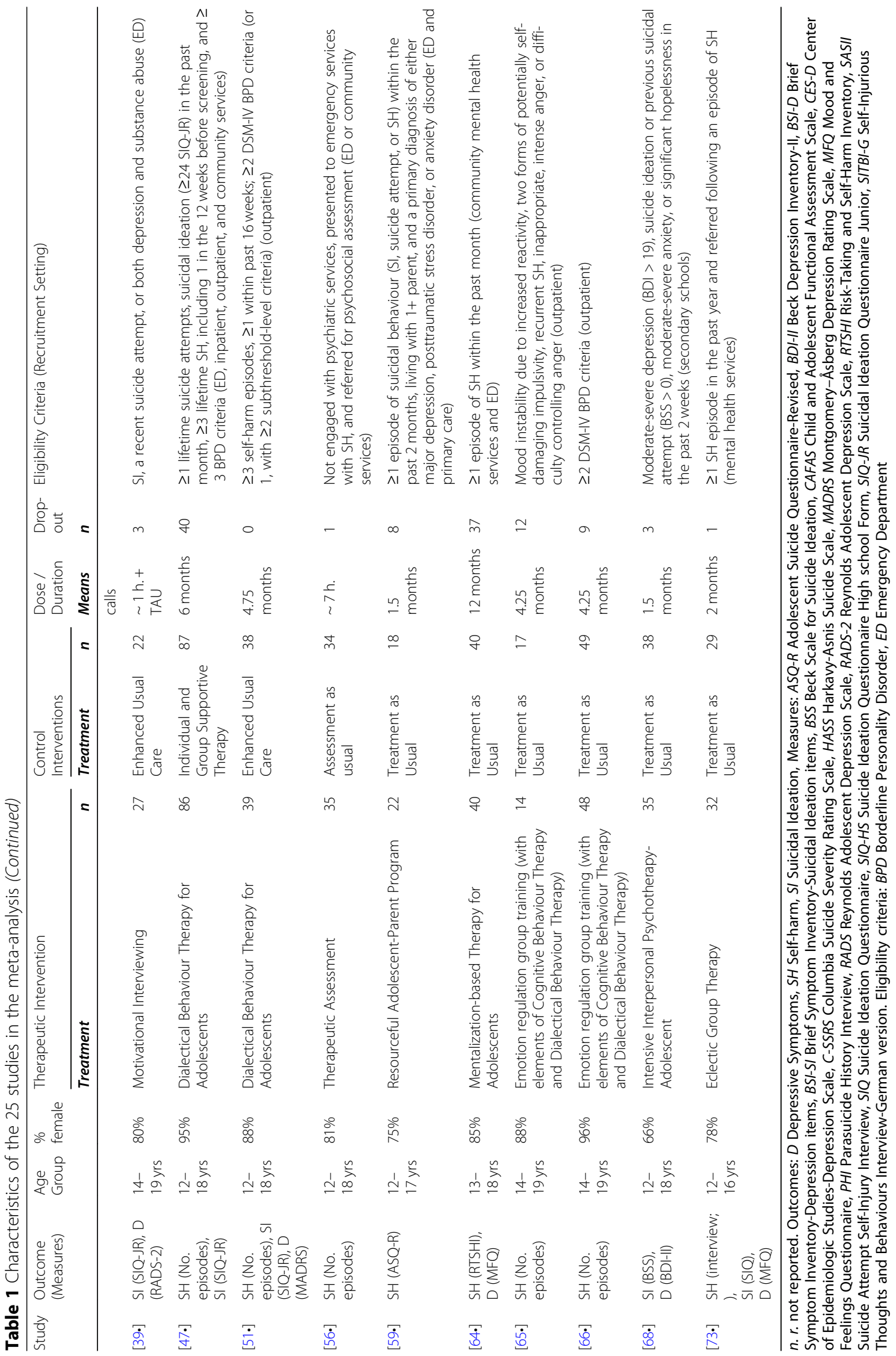


Group Therapy $(n=5,20 \%)$, with the remainder of studies focusing on CBT-based interventions $(n=4,16 \%)$, brief-interventions plus TAU (defined as up to 3 sessions in addition to treatment as usual, $n=4,16 \%$ ), DBT-A $(n=3,12 \%)$, Mentalization-Based Treatment for adolescents (MBT-A; $n=1,4 \%)$, Integrative Therapy $(n=1$, $4 \%)$, Therapeutic Assessment $(n=1,4 \%)$ and Cognitive Analytic Therapy (CAT, $n=1,4 \%$ ). The majority of active controls were comprised of Treatment as Usual (TAU, $n=13,52 \%$ ) and Enhanced Usual Care (EUC, $n=$ $6,24 \%)$. Other active controls used specific therapeutic interventions for comparison $(n=5,20 \%)$ or specific routine care (Assessment as Usual, Hospital Care; $n=1,4 \%$ ).

\section{Control interventions}

Given that TAU and EUC interventions which make up the majority of Control groups are exemplary models of routine clinical care, we first tested the efficacy of these control interventions in reducing self-harm, suicidal ideation, and depressive symptoms. Across 22 studies, ${ }^{1}$ participants receiving standard therapy (e.g., TAU, EUC) as part of active control groups showed moderate to large reductions from pre-to-post intervention in selfharm behaviour $(d=0.60,95 \%$ CI $0.28-0.92, p<.001$, $n=13)$, suicidal ideation $(d=0.87,95 \%$ CI $0.35-1.39$, $p=.001, n=11)$, and depressive symptoms $(d=0.51$, $95 \%$ CI $0.07-0.94, p=.002, n=14)$, suggesting that current routine clinical care is effective at improving patient outcomes.

\section{Efficacy of therapeutic interventions on self-harm} Seventeen effect sizes encompassing 2534 participants (1295 receiving therapeutic interventions and 1239 in active controls) were extracted in order to calculate the overall efficacy of therapeutic interventions, compared to active controls, for reducing self-harm behaviours. Metaanalysis resulted in a significant difference between groups $(d=0.13,95 \%$ CI $0.04-0.22, p=.004)$ with low heterogeneity between studies $\left(I^{2}=2.51 \%\right)$. That is, therapeutic interventions showed a small, but statistically significant, improvement in reducing self-harm behaviours compared to control treatments. See Fig. 2 for a comparison of the effect of therapeutic interventions (compared to control) in reducing self-harm behaviours across different types of therapeutic treatments.

\section{Efficacy of therapeutic interventions on suicidal ideation} Nineteen effect sizes encompassing 2542 participants (1306 receiving interventions and 1236 in active controls) were extracted in order to calculate the efficacy of therapeutic interventions, compared to active controls,

\footnotetext{
${ }^{1}$ Three studies $[40,65,66]$ were omitted due to missing baseline values.
}

for reducing suicidal ideation. Meta-analysis resulted in a significant difference between groups $(d=0.31,95 \% \mathrm{CI}$ $0.12-0.50, p=.001$ ), with high heterogeneity between studies $\left(I^{2}=78.51 \%\right)$ suggesting that therapeutic interventions were moderately more effective at reducing suicidal ideation than treatment in the active control groups. See Fig. 3 for a comparison of the effect of therapeutic interventions (compared to control) in reducing suicidal ideation across different types of therapeutic treatments.

\section{Efficacy of therapeutic interventions on depressive symptoms}

Seventeen effect sizes encompassing 2071 participants (1066 receiving therapeutic interventions, and 1005 in active controls) were extracted in order to calculate the overall efficacy of therapeutic interventions, compared to active controls, for reducing symptoms of depression. Meta-analysis resulted in a significant difference between groups $(d=0.22$, 95\% CI $0.07-0.38, p=.006)$, with moderate heterogeneity between studies $\left(I^{2}=56.70 \%\right)$. That is, therapeutic interventions were moderately more effective at reducing symptoms of depression compared to control treatments. See Fig. 4 for a comparison of the effect of therapeutic interventions (compared to control) in reducing depressive symptoms across different types of therapeutic treatments.

\section{Moderator analyses}

To test whether treatment duration (in months) or proportion of young women in the overall sample (compared to young men) moderated the size of metaanalytic effect between therapeutic intervention and active controls, we conducted a multiple meta-regression (see Table 2 for coefficients). Analyses revealed none of these study aspects influenced the effect size of the difference between the therapeutic interventions and active controls for self-harm, suicidal ideation, or depressive symptom outcomes.

\section{Association between self-harm measure timeframe and treatment efficacy}

Given that the frequency of self-harm may fluctuate considerably across time, the timeframe in which each study measured self-harm is another study characteristic that may be associated with therapeutic treatment efficacy. After weighting for the sample size of each study (i.e., the inverse of the $S E$ ), correlation analysis found no evidence that measurement timeframe was associated with the efficacy of therapeutic interventions $(r=.17, p=.533$; see Fig. 5). This suggests that the magnitude of the difference between therapeutic interventions and active controls in reducing self-harm behaviour did not differ by the timeframe in which self-harm was measured. 


\section{Authors and Year}

Cohen's d [95\% CI]

\section{DBT-A}

Mehlum et al. 2014

McCauley et al. 2018

Submodel $\left(\mathrm{Q}=0.39, \mathrm{p}=0.535 ; \mathrm{I}^{2}=0.0 \%\right)$

CBT

Kaess et al. 2019

Group Therapy

Wood et al. 2001

Hazell et al. 2009

Schuppert et al. 2009

Green et al. 2011

Schuppert et al. 2012

Submodel $\left(\mathrm{Q}=6.65, \mathrm{p}=0.156 ; \mathrm{I}^{2}=19.0 \%\right)$

\section{Family Therapy}

Diamond et al. 2010

Asarnow et al. 2011

Cottrell et al. 2018

Submodel $\left(\mathrm{Q}=1.15, \mathrm{p}=0.563 ; \mathrm{I}^{2}=0.0 \%\right)$

MBT-A

Roussow \& Fonagy 2012

Cognitive Analytic Therapy

Chanen et al. 2008

Brief Interventions + TAU

King et al. 2006

King et al. 2009

Kennard et al. 2018

Submodel $\left(\mathrm{Q}=0.27, \mathrm{p}=0.874 ; \mathrm{I}^{2}=0.0 \%\right)$

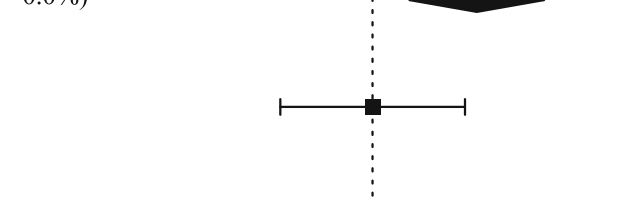

$0.42[-0.03,0.87]$

$0.63[0.14,1.12]$

$0.51[0.18,0.85]$

$0.00[-0.46,0.46]$

$0.53[0.01,1.04]$

$-0.70[-1.72,0.31]$

$0.49[-0.31,1.29]$

$0.07[-0.16,0.30]$

$-0.08[-0.53,0.38]$

$0.11[-0.12,0.34]$

$0.45[-0.29,1.19]$

$0.11[-0.63,0.85]$

$0.04[-0.11,0.19]$

$0.06[-0.09,0.21]$

$0.75[0.14,1.35]$

$0.05[-0.51,0.61]$

$0.12[-0.13,0.38]$

$0.14[-0.16,0.44]$

$-0.01[-0.50,0.49]$

$0.11[-0.07,0.29]$

Therapeutic Assessment

Ougrin et al. 2013

$\operatorname{RE} \operatorname{Model}\left(\mathrm{Q}=19.01, \mathrm{df}=16, \mathrm{p}=0.268 ; \mathrm{I}^{2}=2.5 \%\right)$

Favors Control Intervention

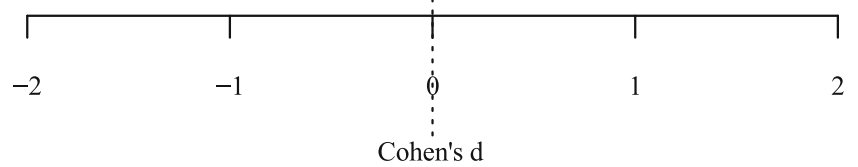

Fig. 2 Forest plot of trials comparing the effect of therapeutic interventions and controls on self-harm. Note: Displays the standardized mean difference (Cohen's $d$ ) in post-treatment self-harm, a positive effect size indicates that the outcome was in favour of therapeutic interventions. The average effect was calculated using a random-effects model

\section{Publication Bias}

Finally, we consider the potential impact of publication bias in the literature examined in these metaanalyses. For each outcome, funnel plots showing each study plotted by study precision and result are presented in Fig. 6. Visual inspection of these funnel plots suggests that across all three outcomes, studies were symmetrically distributed. That is, we found no evidence for publication bias in either the self-harm, suicidal ideation, or depressive symptoms literature included in the present meta-analyses. In addition, Egger's regression found no evidence for funnel plot asymmetry in the analyses of self-harm $(z=1.59$, $p=.112)$, suicidal ideation $(z=1.10, p=.273)$, or depressive symptoms $(z=1.40, p=.162)$. Given that no indication of publication bias was found, no adjustments were needed according to trim-and-fill analysis in all analyses. 


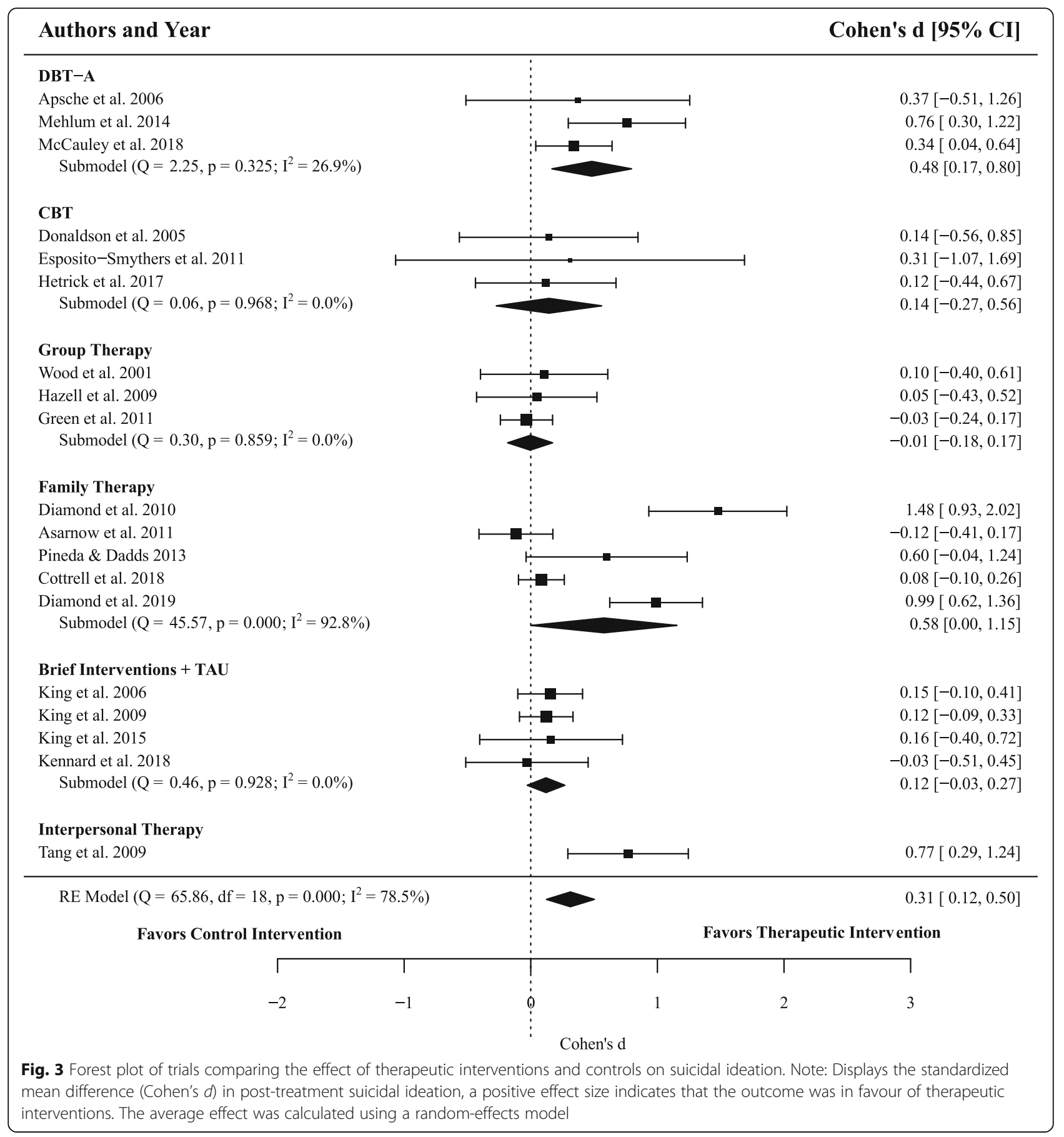

\section{Discussion}

The clinical significance and high prevalence of selfharm and suicidal ideation among adolescents necessitates the establishment of efficacious psychotherapeutic treatments for young people. Given that the literature on therapeutic interventions for adolescent self-harm has proliferated since the last quantitative review [57], we conducted a systematic review and meta-analysis of 25 studies (including 9 studies new to this meta- analysis) focusing on the therapeutic interventions of self-harm and suicidal ideation in adolescents. Given the high degree of overlap between self-harm, suicidal thoughts and behaviours, and depression [27, 55, 63], we also considered depressive symptoms as a secondary outcome. This review addresses the general effects of therapeutic interventions compared to control interventions, as well as specific therapy-related effect-sizes through subgroup analysis. The comparison between 


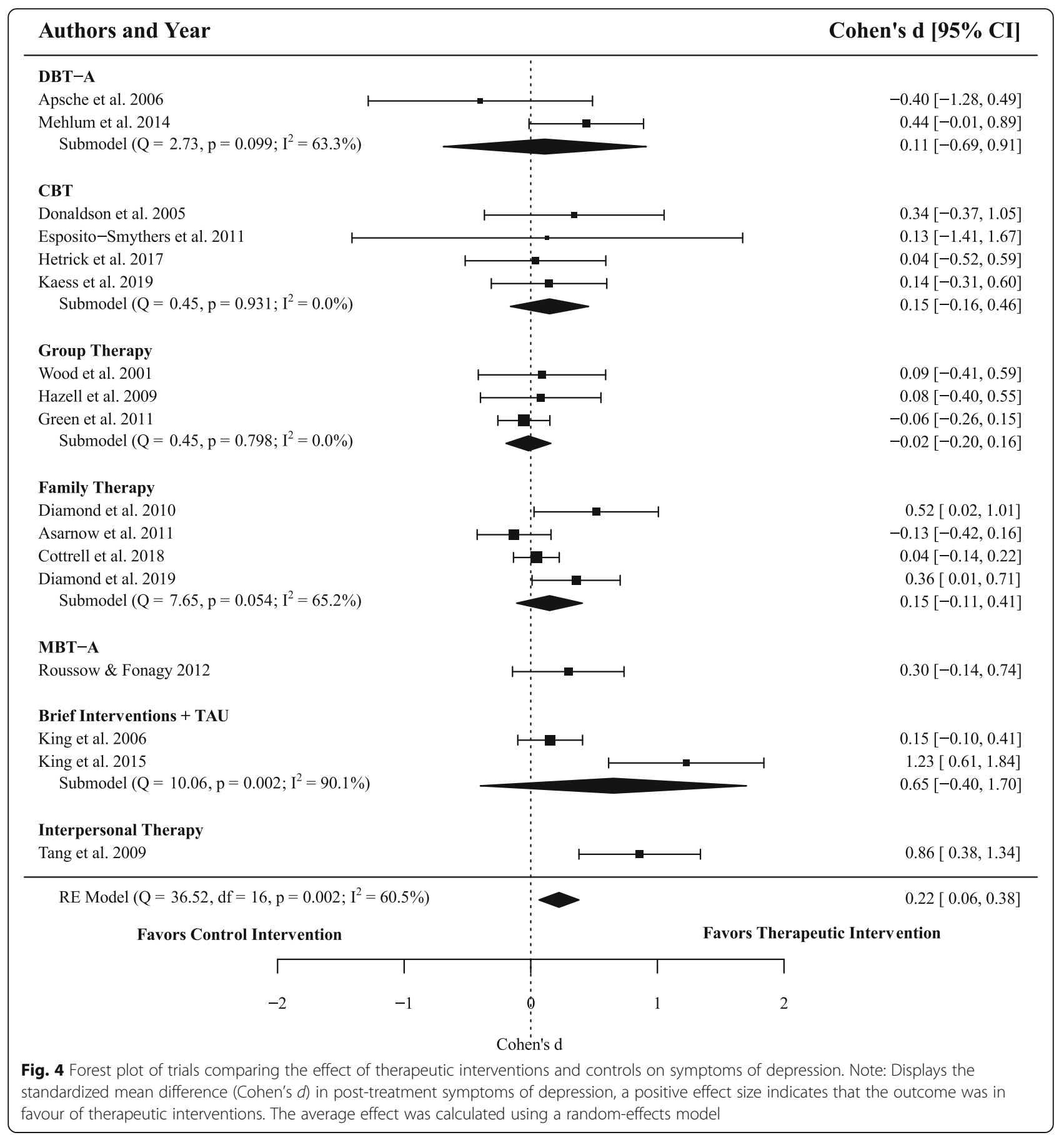

Table 2 Parameters of mixed-effects meta-regression on the efficacy of therapeutic interventions as compared to active controls in self-harm, depressive symptoms, and suicidal ideation

\begin{tabular}{|c|c|c|c|c|c|c|c|c|c|}
\hline \multirow[t]{2}{*}{ Predictors } & \multicolumn{3}{|c|}{ Self-Harm $(\boldsymbol{n}=17)$} & \multicolumn{3}{|c|}{ Suicidal Ideation $(\boldsymbol{n}=19)$} & \multicolumn{3}{|c|}{ Depressive Symptoms $(\boldsymbol{n}=17)$} \\
\hline & $b$ & SE & $p$ & $b$ & SE & $p$ & $b$ & SE & $p$ \\
\hline Treatment Duration (Months) & 0.01 & 0.02 & .712 & -0.01 & 0.05 & .956 & -0.03 & 0.03 & .297 \\
\hline$\%$ Females & -0.15 & 0.61 & .801 & 0.08 & 0.65 & .906 & 0.27 & 0.54 & .621 \\
\hline$R^{2}(Q)$ & \multicolumn{3}{|c|}{$0.00(0.21)$} & \multicolumn{3}{|c|}{$0.00(0.01)$} & \multicolumn{3}{|c|}{$0.00(1.52)$} \\
\hline
\end{tabular}

$n$ number of studies, $b$ unstandardized regression coefficient, SE Standard error of unstandardized regression coefficient. $R^{2}$ Heterogeneity accounted for by predictors 


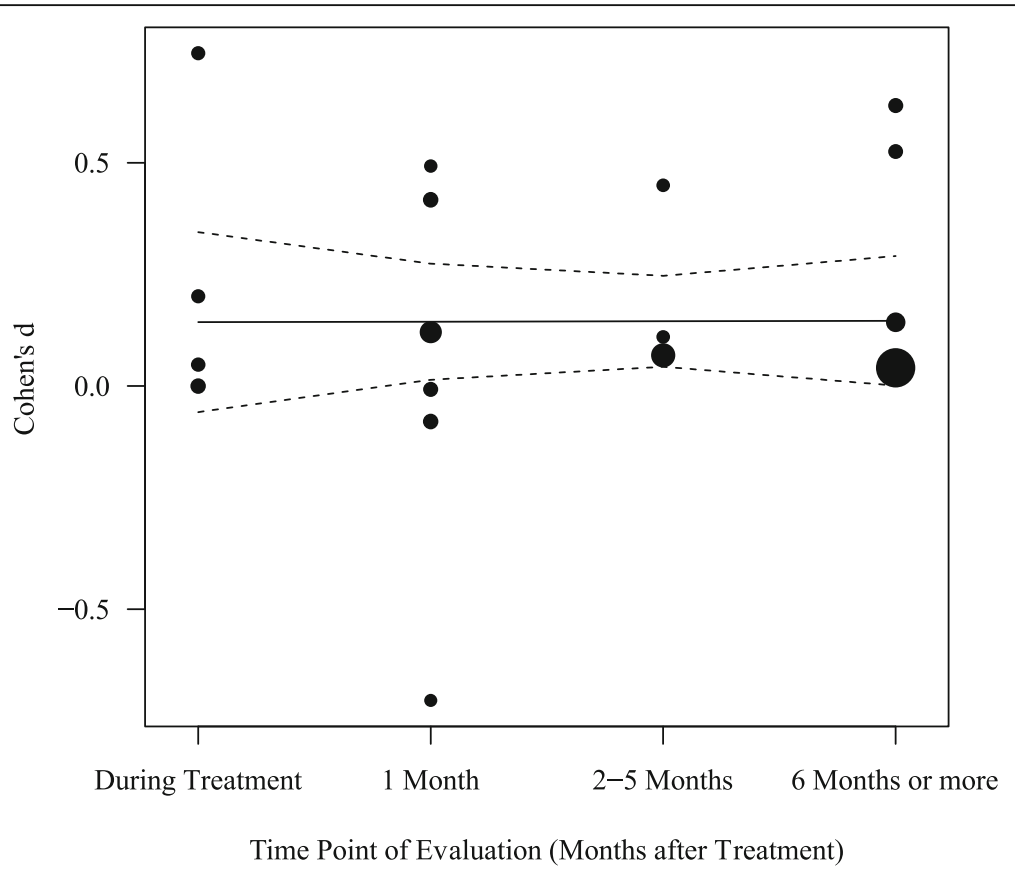

Fig. 5 Effect sizes of the difference between therapeutic interventions and control groups by the time of measurement in self-harm. Note. The radius of the points is drawn proportional to the inverse of the standard errors (i.e., studies with greater statistical power are shown as larger points)

several subgroups of therapeutic interventions allows a more nuanced understanding of the differential effects of treatment type in reducing self-harm, suicidal ideation, and depressive symptoms. Moreover, we assessed whether study characteristics such as self-harm measurement timeframe and gender distribution influenced the meta-analytic effect sizes of therapeutic intervention.

Our results indicate that compared to active control conditions, participants assigned to therapeutic interventions showed significantly greater decreases in self-harm behaviour $(d=0.13)$, suicidal ideation $(d=0.31)$, and depressive symptoms $(d=0.22)$ with small effect sizes. This is in line with former reviews on this topic [20, 21, 57], which also reported on the efficacy of therapeutic interventions in reducing self-harm. However, an overall analysis of participants assigned to exemplary models of routine clinical care (TAU, EUC) as control interventions also showed medium to large effects regarding the reductions in self-harm behaviour $(d=0.60)$, suicidal ideation $(d=0.87)$, and depressive symptoms $(d=0.51)$.

\section{Applicability of the results}

\section{Dialectic Behavioural therapy for adolescents}

Subgroup analysis of specific types of therapeutic intervention revealed that, when compared to active control interventions, only DBT-A showed significantly better
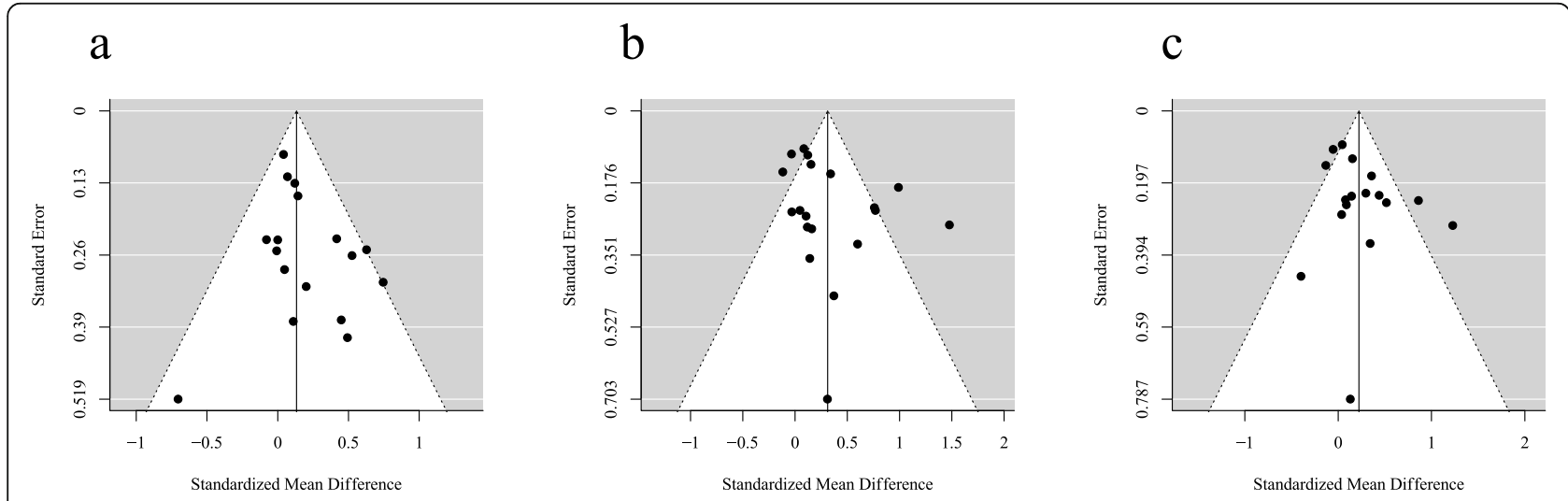

Fig. 6 Funnel plots for (a) self-harm, b suicidal ideation and (c) depressive symptoms, showing limited evidence for publication biases across the three outcomes 
treatment outcomes with a moderate effect $(d=0.51)$. No other types of therapeutic interventions showed improvements when compared to active control interventions. A similar meta-analytic efficacy $(d=0.32)$ has been reported in a review of the effect of DBT in reducing self-harm behaviours in adult samples [12]. Within adolescent samples, we found low heterogeneity in results across studies assessing the efficacy of DBT-A. In terms of therapeutic types most effective for decreasing suicidal ideation, DBT-A also showed a small effect size against control interventions $(d=0.48)$ with moderate heterogeneity in results, and is larger compared to results of the meta-analysis of adult samples $(d=0.23,[12])$.

\section{Family-centred therapies}

In contrast to the pattern of results for self-harm behaviours, family-centred therapies also showed a moderate effect against controls in reducing suicidal ideation $(d=0.58)$. However, as a subgroup family-centred therapies demonstrated a large degree of heterogeneity in results across studies. Notably, the two studies using Attachment-Based Family Therapy $[13,14 \cdot]$ showed the largest effects in reducing suicidal ideation compared to controls. Other studies within this subgroup include a variety of other interventions like family-based CBT [3•], systemic therapy [11•] and resourceful adolescent-parent program [59•]. Thus, the high heterogeneity in results may reflect the variety of interventions subsumed within this subgroup. Unfortunately, this variety limits our ability to draw reliable conclusions for the efficacy of this subgroup of therapeutic interventions, and so further research is needed to better evaluate family-centred therapies.

\section{Promising therapies for future research}

Additionally, two single studies were not assigned to a specific therapy subgroup but showed promising results with moderate to large effect sizes. A study focusing on MBT-A showed good efficacy in reducing self-harm behaviours, but also reported a high number of dropouts during the 12 months of treatment [64•]. Further, one study found a large effect of interpersonal therapy in reducing suicidal ideation and depressive symptoms [68.]. The promise of these two therapeutic interventions should be further tested in additional samples in order to better evaluate their efficacy in reducing self-harm behaviours, suicidal ideation, and depressive symptoms among adolescents.

\section{Pragmatic considerations}

Given that therapeutic treatment for adolescent selfharm and suicidal ideation occurs in a variety of settings (e.g., inpatient clinics, outpatient care, and schools) which vary in the extent of available resources, we next take a pragmatic approach in considering the different therapy types. Both DBT-A and family-centred therapies were found to demonstrate efficacy in reducing suicidal ideation, with DBT-A also showing efficacy in reducing self-harm behaviours. Eligibility for recruitment into family-centred therapy studies was limited to young people with a primary caregiver who was also willing to participate (e.g., $[11,13,14 \cdot])$. Given that young people with a poorer quality of relationship with their family or who experience family stressors are at greater risk of engaging in self-harm [34, 36, 70], family-centred therapies have the potential to reduce family stressors and target behaviour of the young patients and their parents on a systemic level. However, in other cases therapeutic engagement with a primary caregiver may not be beneficial or should be carried out with caution (e.g., in cases of neglect, abuse by a caregiver). Thus, in deciding which therapeutic treatment to implement, consideration of the evidence-base as well as the resources available and the characteristics of the patients should be made.

\section{The possible benefits of treatment as usual}

Across studies included in this meta-analysis, there seems to be an emerging pattern of evidence that TAU or EUC control conditions have the potential to reduce treatment outcomes (weighted pre-post effect sizes for self-harm: $d=0.60$, for suicidal ideation: $d=0.87$, for depressive symptoms: $d=0.51$ ). In particular, experimental conditions only showed a small (although significant) improvement in reducing self-harm over-and-above control interventions. However, these findings should be interpreted with caution, as they may simply result from the time or environmental changes.

An alternative interpretation for this pattern of results is that a high standard of routine clinical care reduces self-harm behaviour, suicidal ideation, and depressive symptoms. In some studies, the reduction of self-harm was achieved faster in experimental conditions, such as CBT $[34,36]$ or DBT-A [47•], but by the endpoint of the study the experimental and active control conditions this difference was attenuated. Given the limited resources available in the field of child and adolescent psychotherapy and psychiatry, it is crucial to understand the mechanisms of change in the control interventions. One hypothesis is that recent years have seen interventions such as skills training and distress tolerance adapted from scientific research of treatment-pathways into routine clinical care, thus raising the efficacy of TAU conditions. Alternatively, it might be the case that adolescents engaging in self-harm behaviours benefit from regular therapeutic contact, regardless of whether this contact follows a pre-defined treatment pathway. In line with this hypothesis, routine clinical care has been demonstrated to be effective in treating adolescent depression [22]. In addition, this finding further underlines 
the results reported for general psychiatric management in adults with Borderline Personality Disorder (BPD), in which a comparable decrease of self-harm and BPD features have been reported from RCTs compared to evidence based treatment standards [25, 48, 49]. Understanding the factors which influence treatment outcome in TAU conditions to further optimize and standardise routine care is of the utmost importance given both the high prevalence of self-harm in adolescence and the restricted availability of therapists trained in special treatment approaches such as DBT-A. Consideration of both of these factors highlights the need for a scalable and easily teachable intervention to address the needs of a larger population.

\section{Limitations}

The generalisability and nuance of the current metaanalyses are limited to a small, but growing, number of studies ( $n=25$ studies eligible for quantitative review). In particular, subgroup analyses were limited by the number of studies within each analysis, with some subgroups only containing one study (e.g., CBT in selfharm, [34, 36]). Thus, these treatment effects should be interpreted with caution, and future trials are needed in order to draw better conclusions in future reviews. Furthermore, the overall analysis revealed high heterogeneity of effects in suicidal ideation as well as depressive symptoms. However, the effects of all studies regarding self-harm showed only small heterogeneity. Another limitation concerns the demographic characteristics of the participants included in these studies. Across studies, young women tend to make up the majority of participants, with only one study in which young men made up $40 \%$ or more of the sample [2•]. In addition, despite growing evidence that transgender and gender-diverse young people have elevated rates of self-harm and suicidality compared to their cisgender peers $[43,69]$, none of the 25 trials included in this meta-analysis reported including any transgender or gender-diverse participants, severely curtailing our ability to assess the efficacy of either routine clinical care or psychotherapeutic treatment in a population with high-levels of clinical need.

\section{Future directions}

Developmental differences in treatment efficacy also represent an area for future research. Although all studies included in the current meta-analyses included participants ranging from young adolescents (12-13 years old) to older adolescents (16-19 years old), no study reported outcomes stratified by age, limiting our ability to understand whether therapeutic efficacy differs across adolescent development. In addition to age-related differences in self-harm behaviour [60], key therapeutic targets such as emotion regulation skills change during early to late adolescence [24, 50]. Thus, future research should include age comparisons to consider not just which treatment intervention is most effective, but when.

Another important area for future research is to determine the optimal treatment setting for young people with severe self-harm. Recent studies have shown that longer inpatient admissions might be linked with increased risk of self-harm in young people [58, 62]. However, the role of hospital treatment, if any, remains to be established in young people with the greatest risk of suicide. Additionally, a standardized definition of what constitutes a recovery from self-harm behaviour (for discussion, see [37]) would increase the ability to compare across studies, as well as help to implement bestpractice standards for evaluating the efficacy of therapeutic intervention.

Finally, given that only a minority of all studies reported data for follow-up assessments (e.g., [52]), little is known about whether the effect of therapeutic interventions in reducing self-harm remains stable over time. Follow-up analyses are of particular importance given preliminary evidence that reductions in self-harm are achieved faster by CBT [34, 36] or DBT-A [47•] than control intervention, but that this difference is attenuated at follow-up [34, 36, 47.]. The stability of therapeutic effects is an important factor in treatment considerations, particularly in resource-poor environments, and future follow-up research is needed to inform this decision-making process.

\section{Conclusion}

The current meta-analysis with an overall sample of 2962 patients found small effect sizes for the reduction of self-harm and suicidal ideation in DBT-A, as well as moderate effect sizes for the reduction of suicidal ideation in family-centred therapy. Given that there is evidence for an increase in rates of self-harm through adolescence with a decline in early adulthood $[19,60]$, future studies should investigate age-specific effects of therapeutic interventions from young adolescents to early adulthood. Indeed, therapeutic interventions to treat self-harm and suicidal ideations for adolescents appear effective, but more research is needed to investigate the efficacy and effectiveness of specific therapeutic interventions.

Summing up the results from the last two decades of investigation into therapeutic interventions for self-harm and suicidal ideation, we conclude that besides DBT-A and family-centred therapy showing small-to-moderate effects, most groups of interventions have similar treatment outcomes to active controls. Nevertheless, control interventions (e.g., TAU, EUC) show large effect sizes in reducing self-harm, suicidal ideation, and depressive symptoms. These findings warrant a closer look at TAU 
treatment standards in clinical care as these standards may include useful components for decreasing selfharm. The efficacy of DBT-A and family-centred therapy (in particular, ABFT) underline the importance for more investigation into the additional benefits from these therapeutic interventions for self-harm and suicidal ideation in the future.

\section{Acknowledgements}

This research was supported in part by an Ernst Mach Grant financed by the Austrian Federal Ministry of Education and Science that was awarded to K.R.

\section{Authors' contributions}

The search was performed by ODK, KR and PLP, calculations were provided by AG and ODK, the manuscript was drafted by PLP, ODK, KR, AG and DO. All authors read and approved the final manuscript. The manuscript has not been submitted or published elsewhere.

\section{Funding}

This research was supported in part by an Ernst Mach Grant financed by the Austrian Federal.

Ministry of Education and Science that was awarded to K.R.

\section{Availability of data and materials}

Data are available from the original manuscripts cited in this meta-analysis.

\section{Ethics approval and consent to participate}

Not applicable as this presents a meta-analysis of pre-existing data.

\section{Consent for publication}

Not applicable.

\section{Competing interests}

All authors declare that they don't have any competing interests regarding this manuscript.

\section{Author details \\ ${ }^{1}$ Department of Child and Adolescent Psychiatry, Medical University of Vienna, Vienna, Austria. ${ }^{2}$ School of Psychology, Victoria University of Wellington, Wellington, New Zealand. ${ }^{3}$ Department of Clinical and Health Psychology, Faculty of Psychology, University of Vienna, Vienna, Austria. ${ }^{4}$ Outpatient Unit for Research, Teaching and Practice, Faculty of Psychology, University of Vienna, Vienna, Austria. ${ }^{5}$ Department of Child and Adolescent Psychiatry, Institute of Psychiatry, Psychology and Neuroscience, King's College London, London, UK. ${ }^{6}$ Department of Child- and Adolescent Psychiatry and Psychotherapy, Medical University of Ulm, Ulm, Germany.}

Received: 8 January 2020 Accepted: 13 April 2020

Published online: 11 May 2020

\section{References}

\section{-Indicates a study included with the meta-analysis.}

1. American Psychiatric Association (APA). Diagnostic and Statistical Manual of Mental Disorder (5th ed.) (DSM-5). Arlington, VA: American Psychiatric Publishing; 2013

2. - Apsche JA, Bass CK, Houston MA. A one year study of adolescent males with aggression and problems of conduct and personality: a comparison of MDT and DBT. Int J Behav Consult Ther. 2006;2(4):544-52.

3. - Asarnow JR, Baraff LJ, Berk M, Grob CS, Devich-Navarro M, Suddath R, et al. An emergency department intervention for linking pediatric suicidal patients to follow-up mental health treatment. Psychiatr Serv. 2011;62(11): 1303-9. https://doi.org/10.1176/ps.62.11.pss6211_1303.

4. Card NA. Applied meta-analysis for social science research. New York: Guilford; 2012.

5. Castellví P, Lucas-Romero E, Miranda-Mendizábal A, Parés-Badell O, Almenara J, Alonso I, et al. Longitudinal association between self-injurious thoughts and behaviors and suicidal behavior in adolescents and young adults: a systematic review with meta-analysis. J Affect Disord. 2017;215:3748. https://doi.org/10.1016/j.jad.2017.03.035.

6. - Chanen AM, Jackson HJ, McCutcheon LK, Jovev M, Dudgeon P, Yuen HP, et al. Early intervention for adolescents with borderline personality disorder using cognitive analytic therapy: randomised controlled trial. Br J Psychiatry. 2008;193(6):477-84. https://doi.org/10.1192/bjp.bp.107.048934.

7. Chesin MS, Galfavy H, Sonmez CC, Wong A, Oquendo MA, Mann JJ, Stanley B. Nonsuicidal self-injury is predictive of suicide attempts among individuals with mood disorders. Suicide Life Threat Behav. 2017;47(5):567-79. https:// doi.org/10.1111/sltb.12331.

8. Cloutier P, Martin J, Kennedy A, Nixon MK, Muehlenkamp JJ. Characteristics and co-occurrence of adolescent non-suicidal self-injury and suicidal behaviours in pediatric emergency crisis services. J Youth Adolesc. 2010; 39(3):259-69. https://doi.org/10.1007/s10964-009-9465-1.

9. Cochrane Collaboration. Review manager (RevMan) [computer program]. Version 5.3. Copenhagen: The Nordic Cochrane Centre; 2014

10. Cohen J. Statistical power analysis for the behavioral sciences. New York: Routledge Academic; 1988.

11. - Cottrell DJ, Wright-Hughes A, Collinson M, Boston P, Eisler I, Fortune S, et al. Effectiveness of systemic family therapy versus treatment as usual for young people after self-harm: a pragmatic, phase 3, multicentre, randomised controlled trial. Lancet Psychiatry. 2018;5(3):203-16. https://doi. org/10.1016/S2215-0366(18)30058-0.

12. DeCou CR, Comtois KA, Landes SJ. Dialectical behavior therapy is effective for the treatment of suicidal behavior: a meta-analysis. Behav Ther. 2019; 50(1):60-72. https://doi.org/10.1016/j.beth.2018.03.009.

13. · Diamond GS, Kobak RR, Ewing ESK, Levy SA, Herres JL, Russon JM, Gallop RJ. A randomized controlled trial: attachment-based family and nondirective supportive treatments for youth who are suicidal. J Am Acad Child Adolesc Psychiatry. 2019;58(7):721-31. https://doi.org/10.1016/j.jaac.2018.10.006.

14. - Diamond GS, Wintersteen MB, Brown GK, Diamond GM, Gallop R, Shelef K, Levy S. Attachment-based family therapy for adolescents with suicidal ideation: a randomized controlled trial. J Am Acad Child Adolesc Psychiatry. 2010;49(2):122-31. https://doi.org/10.1016/j.jaac.2009.11.002.

15. • Donaldson D, Spirito A, Esposito-Smythers C. Treatment for adolescents following a suicide attempt: results of a pilot trial. J Am Acad Child Adolesc Psychiatry. 2005;44(2):113-20. https://doi.org/10.1097/00004583-200502000-00003.

16. Dunlap WP, Cortina JM, Vaslow JB, Burke MJ. Meta-analysis of experiments with matched groups or repeated measures designs. Psychol Methods. 1996:1(2):170-7.

17. Duval S, Tweedie R. A nonparametric "trim and fill" method of accounting for publication bias in meta-analysis. J Am Stat Assoc. 2000;95:89-98. https://doi.org/10.1080/01621459.2000.10473905.

18. - Esposito-Smythers C, Spirito A, Kahler CW, Hunt J, Monti P. Treatment of co-occurring substance abuse and suicidality among adolescents: a randomized trial. J Consult Clin Psychol. 2011;79(6):728-39. https://doi.org/ 10.1037/a0026074.

19. Gillies D, Christou MA, Dixon AC, Featherston OJ, Rapti I, Garcia-Anguita A et al. Prevalence and characteristics of self-harm in adolescents: metaanalyses of community-based studies 1990-2015. J Am Acad Child Adolesc Psychiatry. 2018;57(10):733-41. https://doi.org/10.1016/j.jaac.2018.06.018.

20. Glenn CR, Esposito EC, Porter AC, Robinson DJ. Evidence base update of psychosocial treatments for self-injurious thoughts and behaviors in youth. Clin Child Adolesc Psychol. 2019;48(3):357-92. https://doi.org/10.1080/ 15374416.2019.1591281.

21. Glenn CR, Franklin JC, Nock MK. Evidence-based psychosocial treatments for self-injurious thoughts and behaviors in youth. J Clin Child Adolesc Psychol. 2015;44(1):1-29. https://doi.org/10.1080/15374416.2014.945211.

22. Goodyer I, Dubicka B, Wilkinson P, Kelvin R, Roberts C, Byford S, Breen S, Ford C, Barrett B, Leech A, Rothwell J, White L, Harrington R. Selective serotonin reuptake inhibitors (SSRIs) and routine specialist care with and without cognitive behaviour therapy in adolescents with major depression: randomised controlled trial. BMJ. 2007;335(7611):142. https://doi.org/10. 1136/bmj.39224.494340.55

23. - Green JM, Wood AJ, Kerfoot MJ, Trainor G, Roberts C, Rothwell J, et al. Group therapy for adolescents with repeated self harm: randomised controlled trial with economic evaluation. BMJ. 2011:342. https://doi.org/10. 1136/bmj.d682.

24. Gullone E, Hughes EK, King NJ, Tonge B. The normative development of emotion regulation strategy use in children and adolescents: a 2-year 
follow-up study. J Child Psychol Psychiatry Allied Discip. 2010;51(5):567-74 https://doi.org/10.1111/j.1469-7610.2009.02183.x.

25. Gunderson JG. The emergence of a generalist model to meet public health needs for patients with borderline personality disorder. Am J Psychiatry. 2016;173(5):452-8. https://doi.org/10.1176/appi.ajp.2015.15070885.

26. Hawton K, Saunders KEA, O'Connor RC. Self-harm and suicide in adolescents. Lancet. 2012;379:2373-82. https://doi.org/10.1016/501406736(12)60322-5.

27. Hawton K, Bergen H, Cooper J, Turnbull P, Waters K, Ness J, Kapur N. Suicide following self-harm: findings from the multicentre study of self-harm in England, 2000-2012. J Affect Disord. 2015a;175:147-51. https://doi.org/10. 1016/j.jad.2014.12.062.

28. Hawton K, Witt KG, Salisbury TLT, Arensman E, Gunnell D, Townsend E, et al. Interventions for self-harm in children and adolescents. Cochrane Database Syst Rev. 2015b;12. https://doi.org/10.1002/14651858.CD012013.

29. - Hazell PL, Martin G, McGill K, Kay T, Wood A, Trainor G, Harrington R. Group therapy for repeated deliberate self-harm in adolescents: failure of replication of a randomized trial. J Am Acad Child Adolesc Psychiatry. 2009; 48(6):662-70. https://doi.org/10.1097/CHI.0b013e3181aOacec.

30. Hedges LV. Distribution theory for Glass's estimator of effect size and related estimators. J Educ Stat. 1981;6:107-28. https://doi.org/10.3102/ 10769986006002107.

31. • Hetrick SE, Yuen HP, Bailey E, Cox GR, Templer K, Rice SM, et al. Internetbased cognitive behavioural therapy for young people with suicide-related behaviour (reframe-1T): a randomised controlled trial. Evid Based Mental Health. 2017;20(3):76-82. https://doi.org/10.1136/eb-2017-102719.

32. Higgins JPT, Thompson SG, Deeks JJ, Altman DG. Measuring inconsistency in meta-analyses. Br Med J. 2003;327(7414):557-60. https://doi.org/10.1136/ bmj.327.7414.557.

33. lyengar U, Snowden N, Asarnow JR, Moran P, Tranah T, Ougrin D. A further look at therapeutic interventions for suicide attempts and self-harm in adolescents: an updated systematic review of randomised controlled trials. Front Psychiatry. 2018;9:583. https://doi.org/10.3389/fpsyt.2018.00583.

34. - Kaess M, Edinger A, Fischer-Waldschmidt G, Parzer P, Brunner R, Resch F. Effectiveness of a brief psychotherapeutic intervention compared with treatment as usual for adolescent nonsuicidal self-injury: a single-Centre, randomised controlled trial. Eur Child Adolesc Psychiatry. 2019a. https://doi. org/10.1007/s00787-019-01399-1.

35. Joiner TE, Brown JS, Wingate LR. The psychology and neurobiology of suicidal behavior. Annu Rev Psychol. 2005;56(1):287-314. https://doi.org/10, 1146/annurev.psych.56.091103.070320

36. Kaess M, Eppelmann L, Brunner R, Parzer P, Resch F, Carli V, et al. Life events predicting the first onset of adolescent direct self-injurious behavior-a prospective multicenter study. J Adolesc Health. 2019b. https://doi.org/10. 1016/j.jadohealth.2019.08.018.

37. Kelada L, Hasking P, Melvin G, Whitlock J, Baetens I. "I do want to stop, at least I think I do": an international comparison of recovery from nonsuicidal self-injury among young people. J Adolesc Res. 2018;33(4):416-41. https:// doi.org/10.1177/0743558416684954

38. • Kennard BD, Goldstein T, Foxwell AA, McMakin DL, Wolfe K, Biernesser C, et al. As safe as possible (ASAP): a brief app-supported inpatient intervention to prevent postdischarge suicidal behavior in hospitalized, suicidal adolescents. Am J Psychiatr. 2018;175(9):864-72. https://doi.org/10. 1176/appi.ajp.2018.17101151.

39. • King CA, Gipson PY, Horwitz AG, Opperman KJ. Teen options for change: an intervention for young emergency patients who screen positive for suicide risk. Psychiatr Serv. 2015;66(1):97-100. https://doi.org/10.1176/appi. ps.201300347.

40. - King CA, Klaus N, Kramer A, Venkataraman S, Quinlan P, Gillespie B. The youth-nominated support team-version II for suicidal adolescents: a randomized controlled intervention trial. J Consult Clin Psychol. 2009;77(5): 880-93. https://doi.org/10.1037/a0016552.

41. - King CA, Kramer A, Preuss L, Kerr DC, Weisse L, Venkataraman S. Youthnominated support team for suicidal adolescents (version 1): a randomized controlled trial. J Consult Clin Psychol. 2006;74(1):199-206. https://doi.org/ 10.1037/0022-006X.74.1.199.

42. Lipsey MW, Wilson DB. Practical meta-analysis. Thousand Oaks: Sage; 2001.

43. Liu RT, Sheehan AE, Walsh RF, Sanzari CM, Cheek SM, Hernandez EM. Prevalence and correlates of non-suicidal self-injury among lesbian, gay, bisexual, and transgender individuals: a systematic review and meta- analysis. Clin Psychol Rev. 2019;74:101783. https://doi.org/10.1016/j.cpr.2019. 101783.

44. Lloyd-Richardson EE, Perrine N, Dierker L, Kelley ML. Characteristics and functions of non-suicidal self-injury in a community sample of adolescents. Psychol Med. 2007;37(8):1183-92. https://doi.org/10.1017/ S003329170700027X

45. Mars B, Heron J, Klonsky ED, Moran P, O'Connor RC, Tilling K, et al. Predictors of future suicide attempt among adolescents with suicidal thoughts or non-suicidal self-harm: a population-based birth cohort study. Lancet Psychiatry. 2019;6(4):327-37. https://doi.org/10.1016/S22150366(19)30030-6.

46. May JM, Richardi TM, Barth KS. Dialectical behavior therapy as treatment for borderline personality disorder. Ment Health Clin. 2016;6(2):62-7.

47. - McCauley E, Berk MS, Asarnow JR, Adrian M, Cohen J, Korslund K, et al. Efficacy of dialectical behavior therapy for adolescents at high risk for suicide: a randomized clinical trial. JAMA Psychiatry. 2018;75(8):777-85. https://doi.org/10.1001/jamapsychiatry.2018.1109.

48. McMain SF, Guimond T, Streiner DL, Cardish RJ, Links PS. Dialectical behavior therapy compared with general psychiatric management for borderline personality disorder: clinical outcomes and functioning over a 2year follow-up. Am J Psychiatr. 2012;169(6):650-61.

49. McMain SF, Links PS, Gnam WH, Guimond T, Cardish RJ, Korman L, Streiner $\mathrm{DL}$. A randomized trial of dialectical behavior therapy versus general psychiatric management for borderline personality disorder. Am J Psychiatr. 2009:166(12):1365-74.

50. McRae K, Gross JJ, Weber J, Robertson ER, Sokol-Hessner P, Ray RD, et al. The development of emotion regulation: an fMRI study of cognitive reappraisal in children, adolescents and young adults. Soc Cogn Affect Neurosci. 2012;7(1):11-22. https://doi.org/10.1093/scan/nsr093.

51. - Mehlum L, Tørmoen AJ, Ramberg M, Haga E, Diep LM, Laberg S, et al. Dialectical behavior therapy for adolescents with repeated suicidal and selfharming behavior: a randomized trial. J Am Acad Child Adolesc Psychiatry. 2014;53(10):1082-91. https://doi.org/10.1016/j.jaac.2014.07.003.

52. Mehlum L, Ramberg M, Tørmoen AJ, Haga E, Diep LM, Stanley BH, et al. Dialectical behavior therapy compared with enhanced usual care for adolescents with repeated suicidal and self-harming behavior: outcomes over a one-year follow-up. J Am Acad Child Adolesc Psychiatry. 2016;55(4): 295-300.

53. Moran P, Coffey C, Romaniuk H, Olsson C, Borschmann R, Carlin JB, Patton $\mathrm{GC}$. The natural history of self-harm from adolescence to young adulthood: a population-based cohort study. Lancet. 2012;379(9812):236-43. https://doi. org/10.1016/S0140-6736(11)61141-0.

54. Muehlenkamp JJ, Claes L, Havertape L, Plener PL. International prevalence of adolescent non-suicidal self-injury and deliberate self-harm. Child Adolesc Psychiatry Ment Health. 2012;6:10. https://doi.org/10.1186/1753-2000-6-1.

55. Nock MK, Joiner TE Jr, Gordon KH, Lloyd-Richardson E, Prinstein MJ. Nonsuicidal self-injury among adolescents: diagnostic correlates and relation to suicide attempts. Psychiatry Res. 2006;144(1):65-72. https://doi.org/10.1016/j. psychres.2006.05.010.

56. · Ougrin D, Boege I, Stahl D, Banarsee R, Taylor E. Randomised controlled trial of therapeutic assessment versus usual assessment in adolescents with self-harm: 2-year follow-up. Arch Dis Child. 2013;98(10):772-6 http://dx.doi. org/archdischild-2013-304448.

57. Ougrin D, Tranah T, Stahl D, Moran P, Asarnow JR. Therapeutic interventions for suicide attempts and self-harm in adolescents: systematic review and meta-analysis. J Am Acad Child Adolesc Psychiatry. 2015;54(2):97-107.e2. https://doi.org/10.1016/j.jaac.2014.10.009.

58. Ougrin D, Corrigall R, Poole J, Zundel T, Sarhane M, Slater V, Stahl D, Reavey P, Byford S, Heslin M, Ivens J, Crommelin M, Abdulla Z, Hayes D, Middleton K, Nnadi B, Taylor E. Comparison of effectiveness and cost-effectiveness of an intensive community supported discharge service versus treatment as usual for adolescents with psychiatric emergencies: a randomised controlled trial. Lancet Psychiatry. 2018;5(6):477-85. https://doi.org/10.1016/ S2215-0366(18)30129-9.

59. • Pineda J, Dadds MR. Family intervention for adolescents with suicidal behavior: a randomized controlled trial and mediation analysis. J Am Acad Child Adolesc Psychiatry. 2013;52(8):851-62. https://doi.org/10.1016/j.jaac. 2013.05.015.

60. Plener PL, Schumacher TS, Munz LM, Groschwitz RC. The longitudinal course of non-suicidal self-injury and deliberate self-harm: a systematic 
review of the literature. Borderline Personal Disord Emot Dysregul. 2015;2:2. https://doi.org/10.1186/s40479-014-0024-3.

61. Plener PL, Kapusta ND, Kölch MG, Kaess M, Brunner R. Nicht-suizidale Selbstverletzung als eigenständige Diagnose. Zeitschrift für Kinder-und Jugendpsychiatrie und Psychotherapie. 2012;40:113-20.

62. Reavey P, Poole J, Corrigall R, Zundel T, Byford S, Sarhane M, Taylor E, Ivens J, Ougrin D. The ward as emotional ecology: adolescent experiences of managing mental health and distress in psychiatric inpatient settings. Health \& Place. 2017;46:210-8. https://doi.org/10.1016/j.healthplace.2017.05. 008.

63. Ribeiro JD, Franklin JC, Fox KR, Bentley KH, Kleiman EM, Chang BP, Nock MK. Self-injurious thoughts and behaviors as risk factors for future suicide ideation, attempts, and death: a meta-analysis of longitudinal studies. Psychol Med. 2016;46(2):225-36. https://doi.org/10.1017/ S0033291715001804

64. · Rossouw TI, Fonagy P. Mentalization-based treatment for self-harm in adolescents: a randomized controlled trial. J Am Acad Child Adolesc Psychiatry. 2012;51(12):1304-13. https://doi.org/10.1016/j.jaac.2012.09.018.

65. - Schuppert HM, Giesen-Bloo J, van Gemert TG, Wiersema HM, Minderaa RB, Emmelkamp PM, Nauta MH. Effectiveness of an emotion regulation group training for adolescents - a randomized controlled pilot study. Clin Psychol Psychother. 2009;16(6):467-78. https://doi.org/10.1002/cpp.637.

66. . Schuppert HM, Timmerman ME, Bloo J, van Gemert TG, Wiersema HM, Minderaa RB, et al. Emotion regulation training for adolescents with borderline personality disorder traits: a randomized controlled trial. J Am Acad Child Adolesc Psychiatry. 2012;51(12):1314-23. https://doi.org/10.1016/ j.jaac.2012.09.002.

67. Sterne JAC, Egger M. Regression methods to detect publication and other bias in meta-analysis. In: Rothstein HR, Sutton AJ, Borenstein M, editors. Publication bias in meta-analysis: prevention, assessment and adjustments. New York: Wiley; 2005. p. 99-110.

68. - Tang TC, Jou SH, Ko CH, Huang SY, Yen CF. Randomized study of schoolbased intensive interpersonal psychotherapy for depressed adolescents with suicidal risk and parasuicide behaviors. Psychiatry Clin Neurosci. 2009;63(4): 463-70. https://doi.org/10.1111/j.1440-1819.2009.01991.x.

69. Veale JF, Watson RJ, Peter T, Saewyc EM. The mental health of Canadian transgender youth compared with the Canadian population. J Adolesc Health. 2017;60(1):44-9. https://doi.org/10.1016/j.jadohealth.2016.09.014.

70. Victor SE, Hipwell AE, Stepp SD, Scott LN. Parent and peer relationships as longitudinal predictors of adolescent non-suicidal self-injury onset. Child Adolesc Psychiatry Ment Health. 2019;13:1. https://doi.org/10.1186/s13034018-0261-0.

71. Viechtbauer W. Conducting meta-analyses in R with the metafor package. J Stat Softw. 2010;36:1-48. https://doi.org/10.18637/jss.V036.103.

72. Wilkinson P. Non-suicidal self-injury. Eur Child Adolesc Psychiatry. 2013;22(1): 75-9. https://doi.org/10.1007/s00787-012-0365-7.

73. - Wood A, Trainor G, Rothwell J, Moore ANN, Harrington R. Randomized trial of group therapy for repeated deliberate self-harm in adolescents. J Am Acad Child Adolesc Psychiatry. 2001;40(11):1246-53. https://doi.org/10.1097/ 00004583-200111000-00003.

74. Wyman PA. Developmental approach to prevent adolescent suicides: research pathways to effective upstream preventive interventions. Am J Prev Med. 2014;47(3):S251-6. https://doi.org/10.1016/j.amepre.2014.05.039.

\section{Publisher's Note}

Springer Nature remains neutral with regard to jurisdictional claims in published maps and institutional affiliations.

Ready to submit your research? Choose BMC and benefit from:

- fast, convenient online submission

- thorough peer review by experienced researchers in your field

- rapid publication on acceptance

- support for research data, including large and complex data types

- gold Open Access which fosters wider collaboration and increased citations

- maximum visibility for your research: over $100 \mathrm{M}$ website views per year

At BMC, research is always in progress.

Learn more biomedcentral.com/submissions 